\section{Estudio aleatorio de cirugía radical versus radio- terapia para cáncer cervical estado Ib-IIa}

Fabio Landoni, Andrea Maneo, Alessandro Colombo, Franco Placa, Rodolfo Milani, Patrizia Perego, Giorgio Favini, Luigi Ferri, Costantino Mangioni

III Clinica Ostetrico Ginecologica, University of Milan, Milan, Italy ( $F$ Landoni MD, A Maneo MD,

Prof R Milani $M D$, Prof $C$ Mangioni $M D)$; and Division of Radiotherapy (A Colombo MD, F Placa $M D$, Prof L Ferri MD) and Departments of Pathology $(P$ Perego $M D)$ and Radiology ( $G$ Favini MD), Istituto di Scienze Biomediche S Gerardo, Monza, Milan.

\section{Lancet 1997; 350: 535-540.}

Antecedentes: El carcinoma cervical estado Ib y IIa se puede curar con cirugía radical o radioterapia. Estos dos procedimientos son igualmente efectivos, pero difieren en la morbilidad asociada y tipo de complicaciones. En éste experimento aleatorizado de radioterapia versus cirugía, el propósito fue analizar la sobrevida a 5 años y la tasa y patrón de complicaciones y recurrencias asociadas con cada tratamiento.

Métodos: Entre Septiembre de 1986 y diciembre de 1991, fueron remitidas a nuestro Instituto 469 mujeres con diagnóstico nuevo de carcinoma cervical en estados Ib y IIa. Se aleatorizaron 343 pacientes elegibles: 172 para cirugía y 171 para radioterapia radical. Se suministró radioterapia adyuvante después de la cirugía a las mujeres con estado quirúrgico pT2b o mayor, menos de $3 \mathrm{~mm}$ de estroma cervical preservado, bordes positivos o ganglios positivos. Las medidas primarias de resultado fueron la supervivencia a 5 años y la tasa de complicaciones. El análisis de supervivencia y recurrencia fue por intención de tratar y el análisis de complicaciones fue tratamiento administrado.

Hallazgos: En el análisis de intención para tratar se incluyeron 170 pacientes del grupo de cirugía y $167 \mathrm{del}$ grupo de radioterapia; el tratamiento programado se suministró a 169 y 158 mujeres, respectivamente. 62 de 114 mujeres con diámetros cervicales de $4 \mathrm{~cm}$ o menores y 46 de 55 con diámetros mayores de $4 \mathrm{~cm}$ recibieron terapia adyuvante. Después de un seguimiento promedio de 87 (rango 57-120) meses, la supervivencia total a 5 años y la sobrevida libre de enfermedad fueron idénticas en los grupos de cirugía y radioterapia (83\% y $74 \%$, respectivamente, para ambos grupos). 86 mujeres desarrollaron enfermedad recurrente: $42(25 \%)$ en el grupo de cirugía y $44(26 \%)$ en el grupo de radioterapia. Los factores significativos para la sobrevida en los análisis univariado y multivariado fueron: diámetro cervical, linfangiografía positiva e histotipo adenocarcinomatoso. $48(28 \%)$ de las pacientes del grupo de cirugía tuvieron morbilidad severa comparadas con $19(12 \%)$ de las pacientes del grupo de radioterapia $(\mathrm{p}=0.0004)$.

Interpretación: No hay un tratamiento de elección para el carcinoma cervical en etapa temprana en términos de sobrevida total o libre de enfermedad. La combinación de cirugía y radioterapia tiene la peor morbilidad, especialmente complicaciones urológicas. La terapia óptima para cada paciente debe tener en cuenta factores clínicos tales como el estado menopáusico, edad, enfermedad médica, tipo histológico y diámetro cervical para producir la mejor curación con mínimas complicaciones.

\section{Infección por HIV-1 asociada con morfología anormal de la flora vaginal y vaginosis bacteriana}

Nelson Sewankambo, Ronald H Gray, Maria J. Wawer, Lynn Paxton, Denise McNairn, Fred Wabwire-Mangen, David Serwadda, Chuanjun Li, Noah Kiwanuka-Sharon L Hillier, Lorna Rabe, Charlotte A Gaydos, Thomas C Quinn, Joseph Konde-Lule

Makerere University, Kampala, Uganda ( $N$ Sewankambo MMed. F Wabwire-Mangen PhD, D Serwadda MpH, J Konde-Lule DpH); Johns Hopkins University, Baltimore, $M D$ ( $R$ H Gray $M D$, Prof $D$ McNairn Bsc, C Li MD, C A Gaydos PhD, Prof T C Quinn MD); Rakal Project, Uganda Virus Research Institute, Entebbe, Uganda (N Kiwanuka MB); and University of Pittsburgh, PA, USA ( $S$ L Hillier PhD, L Rabe $B S)$.

\section{Lancet 1997; 350: 546-550.}

Antecedentes: La investigación in-vitro ha sugerido que la vaginosis bacteriana puede aumentar la sobrevida del HIV-1 en el tracto genital. Por lo tanto, nosotros investigamos la asociación de infección HIV-1 con anormalidades de la flora vaginal, incluyendo vaginosis bacteriana y depleción de lactobacilos, después de ajustar para actividad sexual y para presencia de otras enfermedades de transmisión sexual (ETSs).

Métodos: Durante la ronda de vigilancia inicial de nuestro ensayo comunitario de control de ETS para prevención de HIV-1 en el distrito rural de Rakai, suroccidente de Uganda, seleccionamos 4718 mujeres con edades comprendidas entre 15-59 años. Ellas suministraron información en una entrevista, sangre para serología de HIV-1 y sífilis, orina para detección de Chlamydia trachomatis y Neisseria gonorrhoeae, y dos aplicadores vaginales autoadministrados para cultivo de Trchomonas vaginalis y detección por gram de flora vaginal, clasificada por puntaje morfológico cuantitativo estandarizado. Los puntajes de $0-3$ fueron flora vaginal normal (predominantemente lactobacilos). Los puntajes superiores sugirieron reemplazo de los lactobacilos por microorganismos anaerobios, gram negativos (4-6 vaginosis bacteriana intermedia; 7-8 moderada y 9-10 severa).

Hallazgos: La frecuencia de HIV-1 fue del 14.2\% entre las mujeres con flora vaginal normal y $26.7 \%$ entre mujeres con vaginosis bacteriana severa $(p, 0.0001)$. Encontramos una asociación entre vaginosis bacteriana e infección aumentada por HIV-1 entre las mujeres mas 